\title{
Synovectomy of the knee in rheumatoid arthritis
}

\section{Results of surgery}

\author{
A. R. TAYLOR, J. S. HARBISON, AND C. PEPLER \\ From the Oxford Regional Rheumatic Diseases Research Centre, Stoke Mandeville Hospital, Aylesbury
}

It has been shown in Part I that the range of movement in the knee after synovectomy for rheumatoid arthritis may be poor in those patients who show gross destructive changes in the joint at the time of operation. Part II concerns a study undertaken to assess the success of the operation over longer periods and to determine whether the outcome is related to the extent of radiographic changes present in the knee at the time of synovectomy.

\section{Materials and methods}

The patients have been described in Part I. The preoperative assessment, operative technique, and postoperative care for the whole group of 110 knees was the same as that described in Part I; 107 knees were available for the final follow-up which took place at intervals of 6 months to 6 years after operation. Radiographs were taken before the operation and at follow-up.

The postoperative assessment was divided into two parts:

(1) A subjective assessment of the results of surgery, in which the patient was asked to classify the result as excellent, good, fair, or poor.

(2) An objective clinical and radiographic assessment carried out on each patient at 6-monthly intervals initially and then yearly.

(a) For the clinical assessment, the knee was examined for pain, swelling, and range of movement, and the erythocyte sedimentation rate and differential agglutination titre were recorded. The results were expressed as excellent, good, fair, or poor, according to the range of movement and the presence and severity of pain (Table I).

Table I Assessment of objective results

\begin{tabular}{|c|c|c|}
\hline Result & Pain & Range of movement \\
\hline $\begin{array}{l}\text { Excellent } \\
\text { Good } \\
\text { Fair } \\
\text { Poor }\end{array}$ & $\begin{array}{l}\text { None } \\
\text { Occasional ache } \\
\text { Moderate ache } \\
\text { Severe }\end{array}$ & $\begin{array}{l}>120^{\circ} \\
90^{\circ}-120^{\circ} \\
60^{\circ}-90^{\circ} \\
<60^{\circ}\end{array}$ \\
\hline
\end{tabular}

Accepted for publication October 7, 1971. (b) For the radiographic assessment, films were examined by two of us (A.R.T. and J.S.H.) independently for the presence of erosions, narrowing of joint space, patellofemoral arthritis, cyst formation, and secondary osteoarthrosis. These changes were graded as follows: $0=$ no change, $1=$ possible changes, $2=$ moderate changes, $3=$ severe changes.

When a clinical assessment was not available the patient's own assessment was substituted, since the two were found to correlate closely.

\section{Results}

At the final assessment of the results of synovectomy the objective and subjective assessments of the results of surgery were nearly identical (Table II), about 60 per cent. of patients having an excellent or good result.

Table II Overall results of synovectomy. Subjective and objective assessments

\begin{tabular}{|c|c|c|}
\hline Result (per cent.) & Subjective & Objective \\
\hline $\begin{array}{l}\text { Excellent or good } \\
\text { Fair } \\
\text { Poor }\end{array}$ & $\begin{array}{l}58 \cdot 3 \\
26 \cdot 3 \\
15 \cdot 4\end{array}$ & $\begin{array}{l}60 \cdot 8 \\
26 \cdot 8 \\
12 \cdot 4\end{array}$ \\
\hline
\end{tabular}

The results were examined at varying intervals after the operation and the percentage of good or excellent results for various periods of follow-up are set out in the Figure (overleaf). At 6 months 76 per cent. of 110 knees showed a good or excellent result, but by 3 years the percentage had fallen to 55 ; thereafter the number of knees available for examination was small, but four patients maintained an excellent result for $5 \frac{1}{2}$ years, though one had a return of pain and swelling shortly afterwards.

With the passage of time a certain number of knees initially rated as good or excellent were downgraded. This change occurred most frequently during the first 2 years of follow-up and 21 knees were affected. Symptoms had recurred in six knees by 6 months, in eight more by 1 year, in three more by $1 \frac{1}{2}$ years, and a further three by 2 years (Table III, overleaf). 


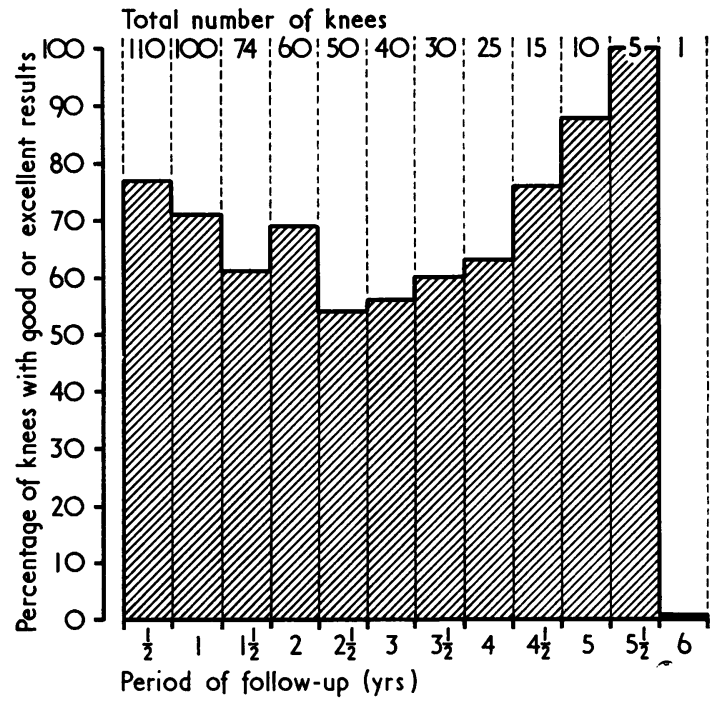

FIGURE Number and percentage of knees with excellent or good results at follow up

Table III Time after which a good or excellent result deteriorated

\begin{tabular}{|c|c|c|}
\hline $\begin{array}{l}\text { Length of } \\
\text { follow-up } \\
\text { (mths) }\end{array}$ & No. downgraded & $\begin{array}{l}\text { Percentage of patients at } \\
\text { risk who were } \\
\text { downgraded }\end{array}$ \\
\hline $\begin{array}{l}6 \\
12 \\
18 \\
24\end{array}$ & $\begin{array}{l}6 \\
8 \\
3 \\
3\end{array}$ & $\begin{array}{l}5 \cdot 6 \\
8 \cdot 4 \\
4 \cdot 3 \\
6 \cdot 0\end{array}$ \\
\hline
\end{tabular}

In only three of the 32 patients who had a bilateral synovectomy was there an appreciable difference between the results of surgery in the two knees. If one knee was downgraded with the passage of time the second knee deteriorated at the same time or within a few months.

In this series, the age at operation, duration of the disease process, sex, titre of rheumatoid factor, and activity of disease as measured by the height of the erythrocyte sedimentation rate had no apparent bearing on the results of surgery.

There was, however, a positive association between the radiographic changes in the knee joint before operation and the final results of surgery (Table IV).

Table IV Relationship between radiographic changes at time of synovectomy and results of surgery

\begin{tabular}{lll}
\hline Radiographic grade & No. of knees & $\begin{array}{l}\text { Per cent. with good } \\
\text { or excellent results }\end{array}$ \\
\cline { 1 - 1 } & 44 & 77 \\
2 & 29 & 52 \\
3 & 17 & 29 \\
\hline
\end{tabular}

The results indicate that, if synovectomy of the knee is carried out before radiographic changes are demonstrable, a satisfactory result will be obtained in the majority of patients. The operation may still be worthwhile in more advanced cases, particularly if more radical surgery is contraindicated.

The radiographs at final follow-up were examined to determine the effect of synovectomy upon the radiographic changes in the joint. There were 87 knees in which radiographs were available for examination throughout the whole period of the follow-up; 66 knees had maintained a good or excellent clinical result, but 60 per cent. of them showed progressive radiographic changes. All the 21 knees initially rated as excellent or good but downgraded during the period of follow-up had radiographic changes before operation and ten of these showed further deterioration. Although a good or excellent result may be maintained for up to 6 years after synovectomy of the knee for rheumatoid arthritis, the joint so treated is not necessarily protected from further destructive changes. However, these changes are often asymptomatic; 46 per cent. of the knees which showed no change before opeartion deteriorated radiographically, but 63 per cent. of those which already had changes before operation showed further deterioration.

\section{Discussion}

The indications for synovectomy of the knee in this group of patients have been persistent pain and swelling for more than 6 months despite adequate conservative treatment, including drugs, splintage, and rest. Radiographs of 75 per cent. of cases selected were normal or showed minimal changes. The immediate value of synovectomy is now widely accepted. Operative removal of synovial membrane from the knee in rheumatoid arthritis will give immediate relief in some two-thirds of patients (Boon-Itt, 1930; Inge, 1938). Aidem and Baker (1964), in reviewing 26 synovectomies of the knee, classified 23 as good or excellent, and Stevens and Whitefield (1966) found that, in 102 cases (100 with rheumatoid arthritis), pain was relieved in all but eight. Barnes and Mason (1967) reported relief of pain in 75 per cent. Our series confirms that an initially good or excellent result may be obtained in some of 76 per cent. of cases, but that in the next 6 years symptoms will return in many. We have shown that a successful result is more likely to be obtained in knees showing no radiographic changes before operation and that this result will be maintained for a longer period of time.

Apart from the degree of joint destruction, as shown in the radiographs at the time of surgery, no feature has been identified in this series which appeared to govern either the immediate results or the recurrence 
of symptoms. We have found that any recurrence of symptoms is most likely to occur in the first 2 years after surgery and that the general disease activity has no bearing on the results of surgery.

It has been shown in animals that a new synovial lining is reformed after synovectomy within 60 days (Kay, 1925; Wolcott, 1927; Mitchell and Blackwell, 1968). In man, after synovectomy, arthrography has demonstrated regrowth of the synovial membrane within 3 months and a normal outline of this membrane (Taylor, 1969). Where gross hypertrophy of the synovial membrane is found at arthrography after operation, there is a clear correlation with the recurrence of symptoms. The factors governing the variation in the regeneration of the synovial lining in man have not been established.

Selection of patients for synovectomy will remain a problem until the results of prospective controlled studies are available. If patients are operated on early in the course of the disease when disability is minimal, surgery in some cases may be unnecessary. However, we have shown that the sooner synovectomy is carried out in relation to the radiographic changes, the more likely is a lasting good result. We have not found any features of the disease, except the radiographic changes, which indicate the prognosis after operative synovectomy. Selection for surgery remains an individual problem. Amongst patients with clear radiographic changes, however, the operation has a less important place.

\section{Summary}

(1) Synovectomy of the knee in patients with rheumatoid arthritis was carried out in 110 knees The patients were followed for from 6 months to 6 years.

(2) Synovectomy appears to be a worthwhile procedure. The initial results were good or excellent in 76 per cent. of cases at 6 months. With time there was a steady deterioration until at 3 years only 55 per cent. maintained their initial benefit.

(3) Radiographic assessment indicated that the more normal the appearance of a joint before operation the better the result.

(4) Those patients whose knees deteriorated with time all showed radiographic changes before operation.

(5) Many patients who maintained an excellent result showed radiographic deterioration in spite of continued freedom from symptoms.

We wish to thank Mr. G. Platt for permission to examine his patients.

\section{References (Part I and II)}

Aidem, H. P., AND BAKer, L. D. (1964) J. Amer. med. Ass., 187, 4 (Synovectomy of the knee joint in rheumatoid arthritis)

Barnes, C. G., AND Mason, R. M., (1967) Ann.phys. Med., 9, 83 (Synovectomy of the knee joint in rheumatoid arthritis)

Boon-ItT, S. B. (1930) J. Bone Jt Surg., n.s. 12, 853 (A study of the end-results of synovectomy of the knee)

GeENS, S., (1969) Ibid., 51 A, 617 (Synovectomy and débridement of the knee in rheumatoid arthritis (Part 1))

-, Clayton, M. L., Leidholt, J. D., Smyth, C. J., and Bartholomew, B. A. (1969) Ibid., 51A, 626 (Synovectomy and débridement of the knee in rheumatoid arthritis (Part 2))

Ghormley, R. K., AND CAmeron, D. M. (1941) Amer. J. Surg., 53, 455 (End results of synovectomy of the knee joint)

INGE, G. A. L. (1938) J. Amer. med. Ass., 111, 2451 (Eighty-six cases of chronic synovitis of the knee joint treated by synovectomy)

KEY, J. A. (1925) J. Bone Jt Surg., 7, 793 (The reformation of synovial membrane in the knees of rabbits after synovectomy)

Leading article (1969) Brit. med.J., 4, 757 (Synovectomy of the knee in rheumatoid arthritis)

LoNDON, P. S. (1955) J. Bone Jt Surg., 37B, 392 (Synovectomy of the knee in rheumatoid arthritis)

Mitchell, N., AND BlACKWELl, P. (1968) Ibid., 50A, 675 (Electron microscopy of regenerating synovium after subtotal synovectomy in rabbits)

Paradies, L. H. (1969) 'Early Synovectomy in Rheumatoid Arthritis', ed. W. Hijmans, W. D. Paul, and H. Herschel, p. 129. Excerpta Medica Foundation, Amsterdam

Stevens, J., AND Whitefield, G. A. (1966) Ann. rheum. Dis., 25, 214 (Synovectomy of the knee in rheumatoid arthritis)

TAYLOR, A. R. (1969) Brit. J. Radiol., 42, 493 (Arthrography of the knee in rheumatoid arthritis)

VAINIO, K. (1969) 'Early Synovectomy in Rheumatoid Arthritis', ed. W. Hijmans, W. D. Paul, and H. Herschel, p. 136. Excerpta Medica Foundation, Amsterdam

Wolcotr, W. E. (1927) J. Bone Jt Surg., 9, 67 (Regeneration of the synovial membrane following typical synovectomy) 